\title{
'At a looking glass' - The Impact of Nursing Schools 'Culture' on Students Professional Socialisation - A Discussion Paper
}

\section{John James Power*}

${ }^{1}$ School of Nursing and Midwifery, Queen's University, Belfast, UK

\begin{abstract}
A discussion paper addressing significant issues in the transference of a culture of care and professionalism to nursing students, from their educational schools. The paper argues that the core values and organisational culture of a school of nursing is integral to the professional socialisation of nursing students with particular focus on care. The paper explores the concept of organisational core values, organisational culture, and the characteristics of leadership in change. The importance of core values, and cultural congruence between the organisation/institution and the nurse educators is explored and emphasized; to more effectively facilitate transfer of these values to students. By way of an example, the paper also explores the management of change within schools of nursing and nurse education and the potential impact/impression that this could make to the development of culture and practice of the nursing student.
\end{abstract}

Keywords: Institutional core values; Institutional culture; Nursing students; Professional socialisation

\section{Introduction}

Caring and collegiality are significant issues within current nursing. Nurse educators significantly impact on student's professional development $[1,2]$ argues that the quality of professional leadership must be reflected within the institutions of nurse education. The environment in which student nurses are educated could significantly impact on their development and professional socialization. Within this context, this discussion paper addresses the idea of organizational core values organizational culture and its transference to and through nurse educators to nursing students, with significant potential for impact on their professional approach to care and nursing practice. The paper also addresses issues in leadership and management and the management of change, again with potentially significant reflection to the en-culturing of student nurses.

\section{Nurse Education and Educators Core Values}

Schools engaged in nurse education should have and reflect clear core values. Core values are defined as 'deeply held views that act as guiding principles for individuals and organizations', informing and shaping organizations and how people relate to each other $[3,4]$. The effective practice of core values should be reflected in performance and companies or organizations 'stand with and inside' their core values [5]. Research suggests that strong core values translate to effective and qualitative practices and the performance of the organization $[6,7]$. Long-term success often reflects an adherence to strong and guiding core values $[8,9]$. Again adherence to strong and visionary core values appears to enhance the motivation and commitment within the organization; with the adherence to quality standards appearing to directly correlate with the presence and practice to core values $[10,11]$. Pendleton and King (ibid) and [12] suggest that core values are inextricably developed from vision; an organization that is well led and well guided. This becomes particularly relevant during periods of stress and significant change. Practice and procedure within successful organizations significantly reflects the organization's vision and values, thus building collective alignment and commitment. This is evident as an inclusive and collective definition of values and practice [13].

If organizations/schools do not clearly define and declare their values, this results in those working within the organization being unclear about what the organization stands for and what the vision really is; without this congruence an organization is weak and shallow. If the expression of core values merely represent 'platitudes' that are not in practice 'honored' or 'upheld' then this reflects in limited staff commitment, poor and shallow practice within the organization [14]. The schools aspirational standards/practices should properly reflect 'collegiality', as significantly contributing to nursing professional practice. Collegiality is defined as a common purpose and commitment; an assemblage of professionals; evidenced by the sharing of power within a structure of relative mutual support and harmony [15]. This is more closely aligned to communities of learning or learning organizations [16] valuing collective relationships/decision making and trans-formational leadership qualities [17] and suggest the importance of teaching and facilitating emotional intelligence as core principles in the nursing curriculum and nursing education. To facilitate the development of emotional intelligence in students would be the reflective/mirror image of the school and organisation, with important need for educators to reflect against a caring scholastic environment. The authors suggest that emotional intelligence is at the heart of learning to care'.

\section{Nurse Education and the Schools Organizational Culture}

Just as with core values the organisational culture of the school of nursing is arguably intrinsic to the professional socialisation of students.

There are a number of models of organizational culture, three of the organisational cultural models will be briefly explored; (i) a functional model (ii) a social action/symbolic interactional model and (iii) a

*Corresponding author: Dr John James Power, School of Nursing and Midwifery, Queen's University, Belfast, UK, Tel: 4402890972392; E-mail: j.power@qub.ac.uk

Received November 23, 2016; Accepted May 09, 2016; Published May 16, 2016

Citation: Power JJ (2016) 'At a looking glass' - The Impact of Nursing Schools 'Culture' on Students Professional Socialisation - A Discussion Paper. Adv Practice Nurs 2:110. doi:10.4172/2573-0347.1000110

Copyright: ( 2016 Power JJ. This is an open-access article distributed under the terms of the Creative Commons Attribution License, which permits unrestricted use, distribution, and reproduction in any medium, provided the original author and source are credited. 
conflict model. A functionalist model of organizational culture would seek to maximise efficiency and loyalty to the company [18]. These organisations seek stability in order to service their functions and work to build and to sustain a culture, which could be 'engineered'. A symbolic interaction/ social action model would focus upon the 'micro' organizational culture rather than the 'corporate' presentation [19], to better understand the driving culture. This approach would carefully analyse what people actually say and do, how they feel about situations and what are the actual shared organizational values and norms rather than the published values; individuals then play the most significant role in thinking, shaping and enacting an organisational culture [20-23]. Finally, the Conflict Theorist in exploring organisational culture would probably place the emphasis within a conflict for limited resources [24-26]. This would represent a microcosm of the political economy; social imbalance, competition for scarce resources, limited employee organizational influence and limited opportunity for advancement. This model presents continual tension, a substantial and unbridgeable resistance between the dominant force of the organisation responding to market drivers and the needs and aspirations of the individual. The organisation is perceived as inherently unstable and features of bureaucracy would be evident within the corporate structure and in the process of imposing the management of change. It is important that the organisations perspective of their culture, and the employee workforce perspective of the organisational culture broadly correspond. Otherwise, this presents as a cultural dissonance.

Without ignoring the complex and multi-dimensional nature of organisational culture, a combination of functional theory and social action theory would suggest that cultural change can be more effectively managed within learning organisations. Lewin's model outlines a process of unfreezing the existing culture and practices, effectively managing the cultural change to the new practices and refreezing. Kotter's model suggests that individuals will make rational choices if they are engaged in the process, that they understand the process and can see the value of the process [27-29]. suggest some degree of flexibility in cultures and that they can be changed through 'cultural importation' in successful organisations. However, as Lewin's model (op sit) and Kotter's model (op sit) implies the changing to new patterns of behaviour requires significant support and reinforcement to those facing the change, and the need to meet the inevitable complexity of a working environment (certainly something as complex as a school of nursing) 'with complexity' [30]. Attitudes should be understood and addressed before seeking to change behaviours [31]. Educators might reasonably feel that they need to be engaged with or effectively consulted about change

A range of studies reflect the importance of congruence both in core values and organisational culture within nursing educators, relative to the impact in the formation of the nursing professional [32] in the introduction to a Brazilian study discuss the significant importance in the professional socialisation of nursing students and their educational experience in developing their professional identity; the professional identity as a reflection of their educative socialization [33] addresses the importance of nursing educators acting as 'role models' in developing an holistic professional and caring approach [34] underline the importance of commitment in significantly helping to form the student nurses' professional identity. An important part of this developing commitment is a reflection from their educators [35]. emphasise the essential core of professional nursing as caring, which particularly includes the formation of attitudes to 'expressive caring' in a recent literature review under-line the impact of role modelling in undergraduate nursing education and the significant impact and influence of nurse academics in the student's professional development.

\section{Nurse Education and the Role of Leadership in the Management of Change}

Effective leadership is crucial to enacting organisational core values and organisational culture and to the effective education of nursing students. Effective leadership is core to the delivery and quality of nursing care [36].

Supported by a significant body of research leadership can be 'transformational'. Transformational leadership more effectively engages collectively and collaboratively, it both creates and inspire vision for change and possibly has more chance of long term effective impact on the organization [37-40]. Central to a transformational style of leadership is effective communication. Communication of the change and the change process should be detailed and honest to engage employees and to address the issues raised within organizational subcultures (ibid.).

Effective communication within complex organisations is critical to their function, development and the successful management of change. A functionalist model might reflect more upon communicating the mechanisms of management focused within bureaucracy, efficiency and expert management. Critical analysis of communication within organisations would suggest that this significantly reflects the working culture rather than the professed values of the organization i.e. an organization would be judged by the quality of its communication. An interpretive approach to communication would view this as an essential living and organic part of the organisation rather than merely as a tool to manage the organisation [41]. Transformational leadership is significantly marked by 'interaction', the building of coalitions and particularly reflects the quality and effectiveness in communicating the change and motivating the workforce $[42,43]$ argues that the quality of effective leadership is integral to the culture of professional nursing. This quality of leadership must be reflected in the schools and universities where nurses are trained 'nursing leadership should, therefore, begin at the earliest stages of basic nursing education and training. Sometimes, the qualities of management and leadership are juxtaposed or confused. Whilst managers in nursing might control parts of the organization, leadership would be marked by inspiration; managers possibly reflect short-term perspectives whilst leadership is marked by vision and a more global perspective; whilst managers may manage change, possibly leaders originate change; managers are sometimes more associated with the status quo, whilst leadership's is marked by significant challenge, 'a leader innovates, inspires, guides, and challenges [44].

\section{Motivation}

Motivation involves ' the instilling in employees of a drive to take action'. Motivation needs to be designed towards the middle to longer term. It should be characterised by both reward and praise with the intention of engaging a positive attitude from employees, organisational commitment and a belief that their individual roles and contribution is valued by and contributes to the organisation. Effective leadership strategy is thought to particularly include the ability to motivate employees and create or contribute to a harmonious workplace [45] suggests that effective leadership is marked by 'emotional intelligence', a key characteristic of which is described as the ability to effectively motivate $[46,47]$ suggests that approaches to management can involve the application or use of Theory X and Theory Y styles of management. The former is marked by directive management of employees to a rather more bureaucratic model to achieve their input to the organization. 
Here positive motivation is not a key component of engaging the employee's attention. By way of contrast theory Y style management would suggest that employees can be very effectively motivated towards self-actualisation if they are engaged, supported and motivated. Management within this model would involve the effective facilitation of that motivation. This model is perhaps particularly appropriate for the management of professional groups.

Collaboration is a participatory process involving individuals and groups within the organisation working to achieve agreed and desired results [48]. This process involves the quality of communication; a prior history of effective and collaborative management of change and decision-making; adequacy of resources (including human resources); a collective or collegiate appreciation of catalysts for change and a history of co-operative working. Finally, a collaborative approach reflects an organisation whose leadership has the ability to build and sustain teams, to interpret diversity as strength and to carry visionary change through effectively. Hertzberg suggests that managers need to be aware of and to build into the working model a structure of motivation [49]. Again this is probably better designed to a collectively collegiate model rather than silos of ambition and competition. Significant parallels might be seen between Hertzberg's motivational hygiene theory and Maslow's model of the hierarchy of needs outlined the principle of the hierarchy of needs. This is also seen within the context of employee engagement and motivation, with safety as a prerequisite i.e. feeling reasonably safe and secure within employment. Social needs are also important, a sense of belonging to and within the organisation. The need for self-esteem is also critical to this model where the employee's contribution is both recognized and their commitment to the organization acknowledged. Ultimately within this model the motivated employee has at least the potential for 'self-actualisation', in achieving their professional potential [50] suggests that managers can motivate employees if incentivizing motivators are designed into the work, 'the hygiene theory'. Significant motivators included achievement, recognition, quality of the working environment responsibility and the potential for advancement. By way of contrast so-called hygiene factors that would increase the employees' dissatisfaction and possible resistance to change would include relationships with managers, the perceived level of commitment of the organization to the employee and sensitivity to work security/ insecurity suggest from a longitudinal UK study of nurse education, that a significant number of students enter nurse education enthusiastic and eager for nurse education, with some significant insight to caring. This motivation to care needs to be, more effectively harnessed within nurse education, reflective in part in humanizing educative curriculum.

\section{Nurse Education and the Management of Change}

The inevitability of change within the structure and practice of nursing. The UK Nursing and Midwifery Council require that all student nurses should be trained/educated in and competent in leadership and understand the core principles and approaches to the management of change.

Change is defined as a dynamic process that responds to 'felt need' (i.e. something that the organization must or should do or respond to) that if affected correctly should positively change the function and values of the organisation [51] suggests that an incremental approach to change can be more effective than radical transformative change; Morrison argues for change to focus within people rather than content. Morrison suggests that change within educational institutions is better affected when there is a 'collegial' response to felt need, with effective communication as a key element and with collegiality significantly helping to build commitment to change suggests that effective leadership involves (inter alia) creating a vision and in turn helping to collectively align, motivate and inspire the organisation or those affected by the change. Effective change management substantially involves building coalitions and importantly rests in the quality of communication. Possibly less effective approaches to the management of change are marked by top-down planning (Sutherland and Change can be managed 'transitionally' where visionary engagement with the workforce is less evident and change is managed through a compliant model involving leaders and followers. Change can also be managed for a particular transaction by using a 'transactional model' of leadership. Here the charismatic and inspirational qualities within the leadership are possibly less necessary.

The role of leadership is crucial in the effective establishment of a new organisational culture and the management of change suggests those qualities of mutuality and the existence of a common purpose between the leader and the group (contrasting with a model of managers and subordinates) is important to effective change management.

Leadership in organizations needs to clearly show that the core values are enacted in policy and in relationship with the workforce. Understanding and effectively engaging the driving culture of an organization is critical to the management of change. If there is evident difference between espoused and enacted values within organizations, then this creates conflict incongruence, dissonance, cynicism, under motivation and a poorly internalised culture.

To take an example from the organization of nurse education; within the UK colleges and schools of nursing, education have moved to universities, with the progressive emphasis on nurse educators focus upon a teaching role to a combined teaching and academic research focus. Approaches to managing change and more effectively welding teaching and research is possibly better facilitated when working to particular strengths, to establish an organizational culture supporting and encouraging diversity and to motivate and enable staff. The quality of leadership is critical to the effective and sensitive management of change and adressed both the inevitability of change within organisations, but particularly within nursing and the importance of inclusion, ownership and identity in change and the potential for reducing resistance to change; with the focus upon an inclusive team better geared to embracing the change. The NHS leadership framework underlines the potential significance and value of all of those involved in the change contributing to change, encouraging a more inclusive approach to change ownership; this can reduce the potential emergence of disproportionate organisational sub-cultures and resistance to change.

\section{Subcultures and Resistance to Change}

Subcultures within organizations are groups separate from the organisational culture and defined by such things as professional occupation; physical separation and the designation of departments. Those within a subculture share similar values and beliefs, probably work within or close to the same department and their work values and beliefs can significantly differ from the dominant culture. Subcultures are sometimes seen as a coping mechanism and the means to preserve the distinctiveness of identity. An effectively functioning organization might be able to both facilitate and to address issues arising within the subculture or countercultures gives the example of an emerging subculture within an educational establishment undergoing a status change to University, where the teaching school's tradition 'strongly rejects' the University values of research and publication. Again the Teachers believed that the school management had either not understood the 
Citation: Power JJ (2016) 'At a looking glass' - The Impact of Nursing Schools 'Culture' on Students Professional Socialisation - A Discussion Paper. Adv Practice Nurs 2:110. doi: 10.4172/2573-0347.1000110

existing subculture or had substantially ignored this within the process of change. An organisational subculture or counterculture should be understood and acknowledged; with any emerging resistance (to change) managed towards a greater consensus. However, failure to detect and to facilitate sub-cultural resistance could de-rail the effective management of change (ibid.).

Within that context, the conflict theorist would suggest that such change it invariably unwelcome, possibly inherently unworkable and will inevitably result in, or produce, significant resistance suggests that many of the problems of leadership are associated with a failure to appreciate the culture but more importantly the subcultures off the organisation. Organisations displaying strong and robust cultures would perhaps be better able to address and indeed facilitate resistance to change. Indeed strong and innovative organisations might actually welcome resistance as a source of fostering innovation and creativity. Alternatively resistance can be internalised and can prove somewhat of a limitation or impediment to necessary change, and within nurse education. This could reflect in a somewhat dislocated relationship between the school/organisation and the nursing student educatorwith again potentially significant impact on the student in observing and an absorbing the effective or ineffective management of change.

\section{Conclusion}

In order to be successful and to deliver a quality of 'product', organisations need clearly defined and enacted core values. These core values should be reflected across the culture of the organisation/school of nursing with a significant thread of core values and culture feeding into the education and professional socialisation of nursing students. Schools of nursing carry a substantial responsibility to embed core values and a culture of care, compassion and collegiality. Core values that talked to collegiality should be reflected within institutional practise. This would be particularly significant within a time of change and particularly where the principles of 'science and caring' should be 'walked' in practice; both to nursing students and to and by their tutors. Schools of nursing could perhaps more consistently and better reflect communities of learning. The leadership of the change should (at least attempt to) be transformational/visionary. An important lesson in leadership for student nurses to take with them.

Core value, and cultural consistency, together with effective leadership are key to engaging academic teaching staff within schools of nursing, to the effective management of change and importantly reflected into the cultural and professional socialisation of nursing students.

\section{References}

1. Anderson D, Anderson LS (2001) Beyond Change Management: Advanced Strategies for Today's Transformational Leader. New York: Jossey-Bass Wiley.

2. Bate $P$ (1995) Strategies for Cultural Change, Oxford: Butterworth-Heinemann

3. Baldwin A, Mills J, Birks N, Budden L (2014) Role modelling in undergraduate nursing education: An integrative literature review. Nurse Education Today 34: e18- e26.

4. Borden L, Perkins D (1999). Assessing your collaboration: A self evaluation tool. Journal of Extension 37.

5. Boswell C, Cannon S (2005) New horizons for collaborative partnershipss. Online J Issues Nurs 10: 3.

6. Bowers B (2011) Managing change by empowering staff. Nurs Times 107: 1921.

7. Bratton P, Sawchuk P, Forshaw C, Callinan M, Corbett M (2010) Work and Organizational Behaviour (2nd edn.) Basingstoke: Palgrave Macmillan.
8. Clements AJ, Kinman G, Leggetter S, Teoh K, Guppy A (2016) Exploring commitment, professional identity, and support for student nurses. Nurse Educ Pract 16: 20-26.

9. Collins JC, Porras Jl (1996) Building your company's vision. Harvard Business 65-77.

10. Cooper MB (2008) Core values and practice success. J Am Dent Assoc 139: 1405-1407.

11. Curtis EA, de Vries J, Sheerin FK (2011) Developing leadership in nursing exploring core factors. Br J Nurs 20: 306-309.

12. Denny E, Earle S (2005) Sociology for Nurses. Cambridge: Polity Press.

13. Finkleman A (2010) Leadership and Management for Nurses Core Competencies for Quality Care (2nd edn.) London: Pearson.

14. Freshwater $D$, Stickley $T(2004)$ The heart of the art: emotional intelligence in nurse education. Nurs Inq 11: 91-98.

15. Goleman D (2002) The New Leaders: Emotional Intelligence at Work. New York: Little Brown.

16. Guffey ME, Almonte R (2010) Essentials of Business Communication. Toronto: Nelson Education.

17. Handel MJ (2003) Sociology of Organizations: Classic, Contemporary and Critical Readings, California: Sage Publications.

18. Herrbach O, Mignonac K (2004) How organizational image affects employee attitudes. Human Resource Management Journal 14: 76-88.

19. Herzberg F (1987) 'One more time: How do you motivate employees?', Harvard Business Review 65: 109-120.

20. Holbeche L (2006) Understanding Change: Theory, Implementation and Success. Oxford: Elsevier.

21. Hurley J, Taylor J (2011) Nurse teaching and research: Symbiotic partners or estranged relatives? Nurse Educ Today 31: 113-114.

22. Khouri R (2011) Impact on educational program nursing students, caring and self-perception intensive clinical training in Jordan. Advances in Medical Education in Practice 2: 173-185.

23. Kotter J (1996) Leading change. Boston: Harvard Business School Press.

24. Kotter J (1998) 21" century leadership. Executive Excellence. 15: 5-6.

25. Leithwoood K, Leonard L, Sharratt L (1998) Conditions Fostering Organizational Learning in Schools. Education Administration Quarterly 34: 243276.

26. Lewin K (1951) Field Theory in Social Science. New York: Harper Row.

27. Loke JCF, Lee KW, Lee BK, Noor AM (2015). Caring behaviors, and student nurses: effects of preregistration Nursing Education in Practice.

28. Lorenzen M (2006) Collegiality and the Academic Library. The Electronic Journal of Academic and Special Librarianship 7.

29. Maslow A (1998) Towards a Psychology of Being. (3rd edtn) London: Wiley.

30. Meyer AD (1982) How ideologies supplant formal structures and shape responses to environments. Journal of Management Studies 19: 45-61.

31. McGregor D (1995) The Human Side of Enterprise. New York: McGraw-Hill Education.

32. Morrison K (1998) Management theories for educational change. California: Sage Publications

33. (2011) National Leadership Council NHS Leadership Framework.

34. Ning M, Murphy P, Jinks AM (2010) Research engagement and attitudes to teaching research to Healthcare Students: a questionnaire study of healthcare educators. Journal of Further and Higher Education 34: 537-556.

35. (2010) Nursing and Midwifery Council (NMC) Standards for pre-registration nursing education.

36. Ogunsola LA, Aboyade WA, Jagboro KO, Igbeneghu IB (2009) Collegiality in the Academic Library -Myth or Reality Ozean Journal of Social Sciences 2: 129-135.

37. O’Meara K, Rice E (2005) Faculty priorities Reconsidered: Rewarding Multiple Forms of Scholarship. San Francisco: Jossey Boss. 
Citation: Power JJ (2016) 'At a looking glass' - The Impact of Nursing Schools 'Culture' on Students Professional Socialisation - A Discussion Paper. Adv Practice Nurs 2:110. doi: 10.4172/2573-0347.1000110

Page 5 of 2

38. Phillips J, Cooper K, Rosser E, Scammell J, Heaslip V, et al. (2015) An exploration of the perception of caring held by students entering nursing programs in the United Kingdom: a longitudinal qualitative study. Phase 1. Nurse education in practice.

39. O'Reilly C, Pfeffer J (2000) Hidden power. Harvard: Harvard Business School Press.

40. Pendleton D, King J (2002) Values and leadership. BMJ 325: 1352-1355.

41. Peters TJ, Waterman RH (1982) In search of excellence: Lessons from America's best run companies. New York: Harper \& Row.

42. Sergiovanni TJ (1994) Organizations or Communities? Changing the Metaphor Changes the Theory. Education Administration Quarterly 30: 214-226.

43. Schein EH (1999) Empowerment Coercive Persuasion and Organizational Learning: do they connect. The Learning Organization 6: 163-172.

44. Shinyashiki GT, Mendes IA, Trevizan MA, Day RA(2006) Professional socialization: students becoming nurses. Rev Lat Am Enfermagem 14: 601-607.
45. Siedman D (2007) How: Why How We Do Anything Means Everything ... in Business (and in Life). Hoboken, N.J: Wiley.

46. Sullivan E, Garland G (2010) Practical Leadership and Management in Nursing London: Pearson.

47. Sutherland J, Canwell D (2004) Key Concepts in Strategic Management, Basingstoke: Palgrave Macmillan.

48. (2009) University of Wollongong (UOW) Academic Promotion: A guide to Evidence about Teaching.

49. Walker J, Payne S, Smith P, Jarrett N (2004) Psychology for Nurses and the Caring Professions (2nd Edn) Maidenhead: OU Pres 232.

50. Whiteley AM, Whiteley J (2007) Core Values and Organizational Change: Theory and Practice. Hackensack NJ: World Scientific Publishing.

51. Witherspoon PD (1997) Communicating Leadership: An Organizational Perspective. Needham Heights, MA: Allyn and Bacon. 